Naskah publikasi skripsi-S1 Igor Yoga Bahtiar (belum diterbitkan)

\title{
KAJIAN RESPON DEBIT MATAAIR NGELENG TERHADAP CURAH HUJAN UNTUK KARAKTERISASI AKUIFER KARST
}

\author{
Igor Yoga Bahtiar \\ igor.bahtiar@gmail.com \\ Tjahyo Nugroho Adji \\ adji@geo.ugm.ac.id
}

\begin{abstract}
Karst aquifer system has heterogeneous - anisotropic characteristic. The uniqueness of karst aquifer gives different evaluation process and understanding of karst aquifer characteristic. The aims of this research are: (1) to understand the correlation pattern between recharge from the rainfall and spring discharge temporally; (2) to analyze spring flow components that are related with response of discharge from rainfall to determine the characteristic of Ngeleng Spring karst aquifer. Evaluation processes was carried out using hydrograph recession analysis and discharge - recharge correlation approach is used to understand the character of aquifer system in study. This research used time series data. Discharge - recharge correlation show quick response which rising discharge about 2-hours time lag after rainfall. The quick response shows that there are rapid flow components (conduit and fissure). The recession analysis also shows there are 3 flow components supply the spring flow, that are diffuse, fissure and conduit.
\end{abstract}

Keywords: Karst Aquifer, Flow Component, Cross Correlation, Rainfall, Discharge

\begin{abstract}
Abstrak
Sistem akuifer karst memiliki sifat heterogen-anisotropis. Keunikan akuifer karst memeberikan perbedaan dalam proses evaluasi dan pemahaman mengenai sifat akuifer karst. Tujuan penelitian ini adalah (1) Mengetahui pola korelasi antara recharge yang berupa curah hujan dengan discharge yang berupa debit pada Mataair Ngeleng secara temporal; (2) Menganalisis komponen aliran mataair yang berkaitan dengan respon debit terhadap curah hujan guna mengetahui karakteristik akuifer karst Mataair Ngeleng. Proses evaluasi dengan analisis resesi hidrograf dan korelasi discharge - recharge menjadi pendekatan untuk mengetahui karakter dari sistem akuifer daerah kajian. Penelitian ini menggunakan data time series. Korelasi discharge - recharge menunjukan respon cepat dengan waktu jeda kenaikan debit 2 jam setelah hujan. Kondisi tersebut mengindikasikan sudah berkembang sistem aliran cepat (aliran celah dan saluran) pada akuifer mataair. Hasil yang sama juga ditunjukan dari analisis resesi hidrograf yang menunjukan terdapat 3 komponen aliran yang menyuplai mataair, yaitu komponen aliran diffuse (rembesan), fissure (celah) dan conduit (saluran).
\end{abstract}

Kata kunci: Akuifer Karst, Komponen Aliran, Cross Correlation, Hujan, Debit

\section{PENDAHULUAN}

Terdapat kurang lebih $12 \%$ permukaan bumi yang terbebas dari tutupan es yang ditempati oleh batuan karbonat dan 7-10\% darinya merupakan bentukan karst (Ford dan William, 2007; Haryono dan Adji, 2004; Haryono et al, 2009; Adji, 2005; Adji dan Hariadi, 2009). Menurut Balazs (1968) dalam Adji (2010, 2012) mengungkapkan bahwa luas kawasan karst di Indonesia mencapai 20\% dari total wilayah Indonesia. Kawasan karst yang cukup luas tersebut memiliki potensi sumberdaya air yang luar biasa (Adji and Haryono, 1999; Adji et al, 1999). Karst merupakan bentukan permukaan bumi yang berkembang dengan adanya porositas sekunder pada batuan yang mudah larut serta memiliki sistem drainase yang khas (Ford dan Williams, 2007). Suatu kawasan karst akan memiliki sistem drainase bawah permukaan yang berbeda dengan kawasan 
Naskah publikasi skripsi-S1 Igor Yoga Bahtiar (belum diterbitkan)

lainnya. Pada dasarnya sistem akuifer karst memiliki sifat heterogen anisotropis, yaitu sifat konduktivitas hidrolik yang bervariasi berdasarkan formasi batuan yang berkembang karena porositas sekunder. Kondisi tersebut memeberikan perbedaan dalam proses evaluasi dan pemahaman mengenai sifat akuifer karst (Adji, 2013; Adji 2014; Adji 2010; Adji, 2011; Adji, 2015).

Salah satu teknik identifikasi perilaku atau karakter akuifer karst adalah dengan mengetahui respon akuifer karst terhadap imbuhan air (Recharge) yang masuk ke dalam sistem akuifer tersebut. Respon akuifer karst yang dimaksud adalah pelepasan (discharge) debit aliran airtanah karst dan recharge yang dimaksud adalah curah hujan. Proses evaluasi dengan analisis resesi hidrograf (Adji et al, 2014), dan korelasi discharge - recharge menjadi pendekatan untuk mengetahui karakter dari sistem akuifer daerah kajian. Upaya proses evaluasi tersebut menggunakan data time series.

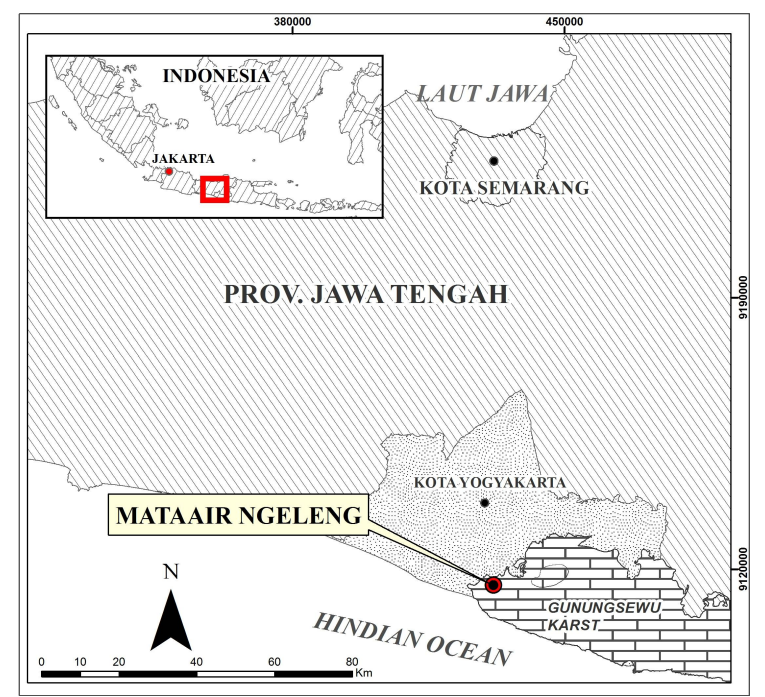

Gambar 1. Peta Obyek Kajian Mataair Ngeleng (Sumber: Olah Data Sekunder, 2014)

Penelitian ini mengambil daerah kajian di Kawasan Karst Gunungkidul, tepatnya berada di sisi sebelah barat kawasan ini. Pelepasan airtanah karst diwakili oleh mataair yang dijadikan sebagai obyek kajian. Mataair Ngeleng yang berada di Desa Giritirto, Kecamatan Purwosari, Kabupaten Gunungkidul merupakan mataair yang dijadikan sebagai obyek kajian.

Berdasarkan penjelasan di atas maka penelitian ini memiliki tujuan secara umum untuk memahami lebih dalam bagaimana perilaku akuifer karst suatu daerah. Memahami perilaku akuifer karst merupakan cara untuk mengetahui karakateristik akuifer tersebut. Maka secara lebih rinci penelitian ini memiliki dua tujuan, yaitu: (1) Mengetahui pola korelasi antara recharge yang berupa curah hujan dengan discharge yang berupa debit pada Mataair Ngeleng secara temporal; (2) Menganalisis komponen aliran mataair yang berkaitan dengan respon debit terhadap curah hujan guna mengetahui karakteristik akuifer karst Mataair Ngeleng.

\section{METODE PENELITIAN}

Penelitian ini membutuhkan data secara time series. Data tersebut dikumpulkan secara langsung dari lapangan. Sehingga data yang diperoleh dapat merepresentasikan kondisi alami di daerah kajian. Data-data yang dikumpulkan adalah:

a. Data TMA Mataair Ngeleng: data didapatkan dengan pengukuran di lapangan menggunakan alat ukur tinggi muka air otomoatis (water level data logger).

b. Data Debit Mataair Ngeleng: data debit mataair didapatkan secara langsung di lapangan dengan pengukuran menggunakan metode pelampung. Pengukuran dilakukan secara berkala, untuk mendapatkan variasi data berdasarkan tinggi muka air.

c. Data Curah Hujan: data ini didapatkan dengan memasang alat penangkar hujan otomatis (automatic rain gauge data logging).

Periode pengambilan data pada penelitian ini dilakukan selama 9 bulan, dimulai pada pertengahan bulan Agustus 2013 hingga bulan Mei 2014.

\section{Teknik Pengolahan Data Tujuan Pertama:}

a. Lengkung Debit (Rating Curve) Mataair

Schulz (1979) menyatakan bahwa tinggi muka air pada suatu aliran dapat memberikan estimasi debit alirannya. Dengan analisis regresi, kurva aliran (stage-discharge rating curve) dapat menghasilkan persamaan sebagai berikut:

$\mathrm{Q}=f \cdot T M A$

Keterangan:

Q : Debit aliran $\left(\mathrm{m}_{3} / \mathrm{s}\right)$

f : Fungsi regresi TMA dengan debit aliran

TMA : Tinggi muka air

b. Korelasi Dua Variabel (Bivariate) 
Naskah publikasi skripsi-S1 Igor Yoga Bahtiar (belum diterbitkan)

Analisis korelasi dua variabel dilakukan untuk mengetahui hubungan dua variabel. Korelasi bivariate memiliki persyaratan data, dimana data harus kontinu, homogen dan distribusi data normal serta regresi data linier (Hartono, 2008). Pada penelitian ini korelasi dua variabel digunakan untuk mengkorelasikan data curah hujan dan debit aliran Mataair Ngeleng. Tujuan dari korelasi tersebut adalah untuk mengetahui gambaran awal arah korelasi kedua variabel tersebut. Penentuan korelasi dua variabel pada penelitian ini menggunakan software SPSS 16. Analyze, Correlate, Bivariate.

c. Cross correlation

Metodologi korelasi silang secara luas digunakan untuk menganalisis hubungan linear antara input dan output dalam kajian hidrogeologi. Secara lebih khusus metode ini juga digunakan dalam analisis sistem karst tentang respon hidrograf mataair terhadap curah hujan seperti yang dilakukan oleh Budge dan Sharp, 2009; Fiorillo dan Doglioni, 2010; serta Zhang, Chen, Chen, dan Shi, 2013.

Korelasi silang (Cross Correlation) merupakan salah satu metode yang banyak digunakan dalam analisis data secara time series. Metode ini dapat digunakan sebagai alat untuk memprediksikan suatu hubungan suatu series data $x$ (input) dengan data $y$ (output) pada suatu sistem. Untuk melakukan analisis korelasi silang, kedua seri tersebut harus sampel dalam interval waktu yang sama dan diasumsikan stasioner dalam mean dan varians (Cowpertwait dan Metcalfe, 2009, Shumway dan Stoffer, 2006, dalam Thomas, 2010). Hubungan kedua variabel tersebut didefinisikan dalam rumus:

$r_{x y}(k)=\frac{C x y(k)}{\sqrt{C_{x}^{2}(0) C_{y}^{2}(0)}}$

Dimana nilai Czy (k) merupakan cross correlogram. Puncak dari garfik cross correlogram (nilai rxy (k) tertinggi) merupakan estimasi time lag (waktu jeda) yang menunjukan cross correlation antara input dan output sistem.

$$
\begin{aligned}
& C_{\mathrm{xy}}(k)=\frac{1}{n} \sum_{t=1}^{n-k}\left(x_{\mathrm{t}}-\bar{x}\right)\left(y_{\mathrm{t}+\mathrm{k}}-\bar{y}\right) \ldots \ldots \ldots \ldots \ldots . . . . . . . . \\
& C_{\mathrm{x}}(0)=\frac{1}{n} \sum_{t=1}^{n}\left(x_{\mathrm{t}}-\bar{x}\right)^{2}
\end{aligned}
$$

$$
C_{\mathrm{y}}(0)=\frac{1}{n} \sum_{t=1}^{n}\left(y_{\mathrm{t}}-\bar{y}\right)^{2} .
$$

Sedangkan Cx (0) dan Cy (0) merupakan rumus standar deviasi untuk masingmasing data series variabel $\mathrm{x}$ dan variabel $\mathrm{y}$.

\section{Teknik Pengolahan Data Tujuan Kedua:}

a. Perhitungan konstanta resesi

Konstanta resesi banjir yang telah dipilih pada berbagai komponen aliran dapat dicari dengan persamaan:

$\mathbf{Q}_{(\mathrm{t})}=\mathbf{Q}_{(\mathrm{t}))} \mathbf{e}^{-\mathbf{k}(\mathrm{t}-\mathrm{t} \mathbf{0})}$

Keterangan:

$\mathrm{k}=$ konstanta resesi suatu sistem karst

$\mathrm{Q}(\mathrm{t})=$ Debit pada waktu ke $\mathrm{t}$

$\mathrm{Q}(\mathrm{t} 0)=$ Debit pada waktu awal segmen resesi

Kemudian jika pada skala semi-log rumus ini dianggap linier, maka:

$$
\ln Q_{(t)}=-\mathbf{k}_{(t-10)}+\ln \mathbf{Q}_{(\mathbf{t} 0)}
$$

(7)

Atau

$k=-1 / t-t 0 \ln \left(Q_{(t)} / Q_{(0)}\right)$

(8)

Nilai konstanta resesi tersebut digunakan untuk menentukan karakteristik aliran pada akuifer karst (Adji et al, 2009, Adji et al, 2007; Adji and Misqi, 2010). Variasi nilai konstanta resesi masing-masing komponen aliran menurut Schulz (1976), yaitu 0,2 - 0,5 untuk Channel flow/aliran conduit; $0,5 \quad-\quad 0,8$ untuk interflow/aliran fissure dan 0,85 - 0,98 untuk baseflow/aliran diffuse. Sedangkan Nathan and McMahon (1990; dalam Adji, 2006) jangkauan nilai konstanta resesi masing-masing komponen aliran berkisar 0,2 - 0,8 untuk channel flow; 0,7 - 0,94 untuk intermediate flow; dan 0,93 0,995 untuk baseflow.

\section{b. Pemisahan Aliran dasar}

Schulz (1976) dan Eckhardt (2012) menyebutkan bahwa tujuan dari pemisahan aliran dasar adalah untuk memberdakan komponen aliran dasar dengan komponen aliran langsung atau aliran cepat pada suatu sistem hidrologi. 
Naskah publikasi skripsi-S1 Igor Yoga Bahtiar (belum diterbitkan)

Metode yang digunakan dalam memisahkan aliran dasar selam periode penelitian adalah dengan menggunakan cara automated baseflow separation by digital filtering (Eckhardt, 2005).

$q b(i)=\frac{\left(1-B F I_{\max }\right) a q_{b(i-1)}+(1-a) B F I_{\max } q_{i}}{1-a B F I_{\max }}$

qb(i) : Aliran dasar pada waktu i

qb(i-1) : Aliran dasar pada waktu i - 1

a $\quad$ : Konstanta resesi aliran dasar $(\mathrm{Kb})$

BFImax :Indeks aliran dasar maksimum (Media porus dan perennial $\mathrm{BFI}_{\max }=0,8$ )

\section{HASIL DAN PEMBAHASAN}

Selama periode penelitian data yang diperoleh dari perekaman di lapangan menghasilkan kurang lebih 13.860 data tinggi muka air (TMA) yang direkam dalam durasi 30 menit. Data TMA tersebut dikonversi menjadi data series debit menggunakan rating curve antara TMA dengan debit yang diukur secara manual. Sedangkan data curah hujan didapatkan dari setiap kejadian hujan. Gambar 1. Merupakan representasi data selama penelitian. Kedua data ini yang digunakan selanjutnya untuk melakukana analisis korelasi Bivariate, cross correlation, penentuan resesi hidrograf dan pemisahan aliran dasar.

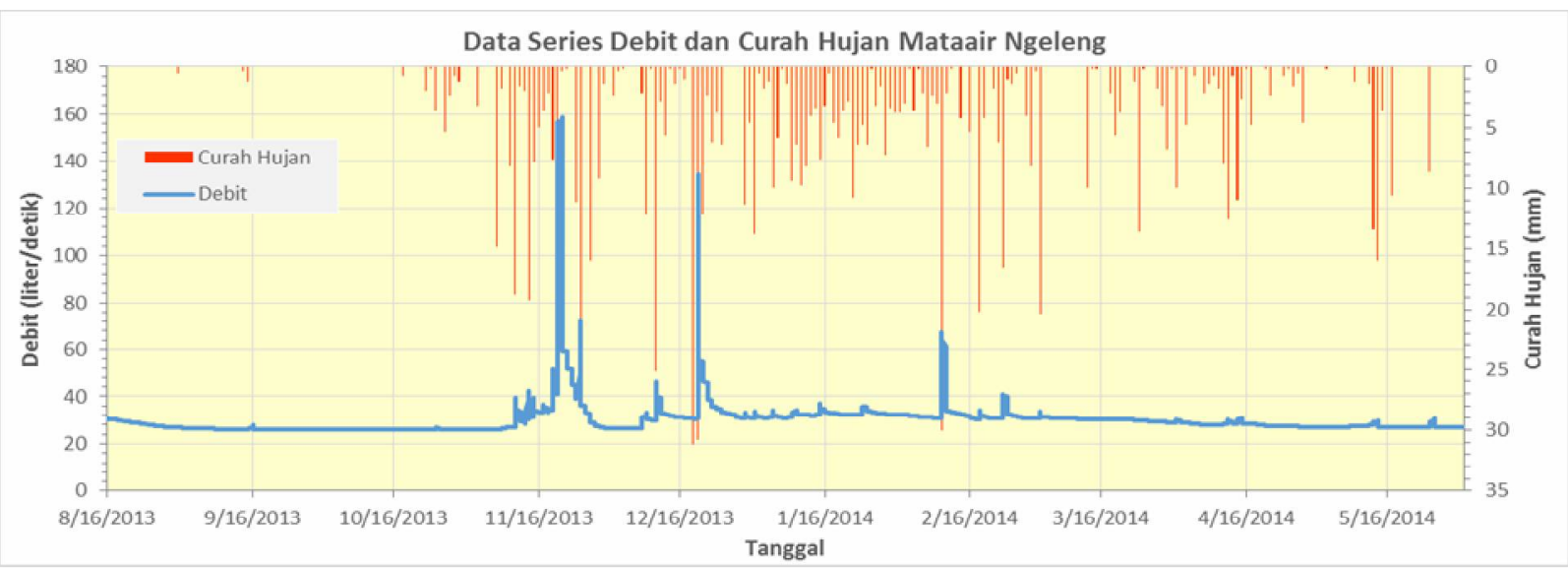

Gambar 1. Grafik Debit Mataair dan Curah Hujan Mataair Ngeleng Periode Penelitian

(Sumber: Pengukuran lapangan, 2013-2014)

Analisis pertama yang dilakukan adalah dengan mengkorelasikan antara curah hujan dengan debit mataair. Curah hujan harian dan rerata debit mataair harian merupakan data yang digunakan untuk mengkorelasikan input dan output pada sisten akuifer karst ini. Korelasi ini bertujuan untuk mengetahui gambaran awal hubungan antara kedua variabel ini dalam kaitannya dengan sistem akuifer. Grafik pada Gambar 2 menunjukan hasil korelasi kedua series data tersebut.

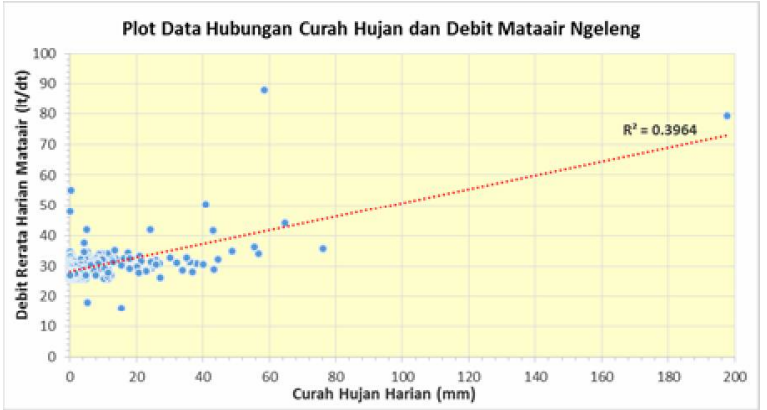

Gambar 2. Grafik Hubungan Curah Hujan Harian dengan Rerata Debit Harian Mataair Ngeleng.

(Sumber: Olah data primer, 2014)

Berdasarkan grafik di atas diketahui bahwa hubungan antara curah hujan harian daerah kajian dengan rerata debit Mataair Ngeleng memiliki nilai korelasi (R) sebesar 0,630. Nilai korelasi tersebut dalam uji statistik menggunakan SPSS memenuhi taraf signifikasi $0,05(5 \%)$, yaitu nilai probabilitas lebih kecil dari 0,05 . Sehingga dapat diartikan bahwa nilai korelasi tersebut signifikan dan terdapat korelasi antara curah hujan dan debit mataair. Besar nilai $\mathrm{R}$ menunjukan tingkat korelasi pada klasifikasi hubungan variabel yang kuat. Selain itu nilai $R$ positif memberikan pemahaman bahwa hubungan antara variabel bebas (Curah Hujan) dan variabel terpengaruh (Debit mataair) berbanding lurus. Bertambahnya curah hujan akan diikuti dengan kenaikan debit mataair. Korelasi sederhana dua 
Naskah publikasi skripsi-S1 Igor Yoga Bahtiar (belum diterbitkan)

variabel ini setidaknya memberikan prespektif bahwa curah hujan sebagai recharge sistem akuifer memiliki hubungan positif terhadap debit mataair sebagai discharge akuifer. Hubungan positif tersebut merupakan hubungan yang berbanding lurus, yaitu ketika terjadi penambahan curah hujan maka akan diikuti dengan bertambahnya debit aliran mataair.

Gambar 3. menunjukan hasil cross correlation dua data series (curah hujan dan debit aliran Mataair Ngeleng). Korelasi yang perlu diperhatikan adalah korelasi pada time lag (waktu jeda) postif. Hal tersebut didasari oleh hasil korelasi Bivariate sebelumnya (Gambar 3.) yang juga menunjukan korelasi positif. Fungsi korelasi silang curah hujan dan debit mataair karst menunjukan hubungan $k$ (time lag) kearah positif yang menunjukan bahwa curah hujan mempengaruhi laju aliran debit mataair (Zhang, Chen, Chen dan Shi; 2013). Nilai korelasi (rxy(k)) tertinggi berada pada time lag jam ke 2 dengan nilai korelasi sebesar 0,281. Sehingga dapat diartikan bahwa akuifer karst Mataair Ngeleng memiliki respon berupa kenaikan aliran debit mataair pada jeda waktu 2 jam dari awal kejadian hujan. Atau dengan kata lain, kenaikan debit mataair dimulai setelah 2 jam dari awal terjadi hujan di daerah tangkapan air. Kenaikan debit mataair yang dimaksud adalah kenaikan debit rata-rata yang bukan merupakan puncak banjir maupun kenaikan secara signifikan berupa banjir.

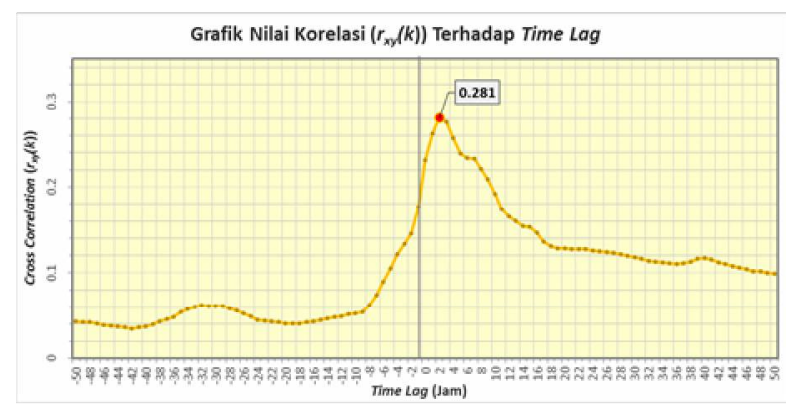

Gambar 3. Correlogram Cross Correlation Debit Mataair Ngeleng Terhadap Curah Hujan (Sumber: Olah data primer, 2014)

Diketahui bahwa hasil cross correlation series data debit dan hujan keseluruhan menghasilkan nilai korelasi respon debit terhadap curah hujan tertinggi adalah pada time lag 2,0 jam. Apabila dikomparasikan dengan data faktual waktu jeda kenaikan debit aliran mataair dari awal kejadian hujan beberapa sampel kejadian banjir, maka hasil cross correlation tidak jauh berbeda. Nilai rata-rata time lag dari keseluruhan kejadian banjir adalah 2,03 jam.

Selain melihat nilai rata-rata time lag dari beberapa kenaikan debit aliran, untuk melihat kebenaran hasil perhitungan cross correlation juga dapat dilakukan dengan cara lain. Salah satunya adalah dengan melihat sebaran nilai time lag yang di hubungkan dengan jumlah curah hujan disetiap kejadian banjir. Hubungan tersebut tergambarkan pada scatter plot Gambar 4. Pada gambar tersebut dapat diketahui bahwa banyak nilai time lag dari besar curah hujan yang bervariasi memiliki kecenderungan pada range nilai $0,5-3$ jam. Sehingga dapat dikatakan bahwa hasil perhitungan cross correlation tidak menyimpang dari kecenderungan nilai faktual time lag respon discharge/debit terhadap recharge/curah hujan Mataair Ngeleng.

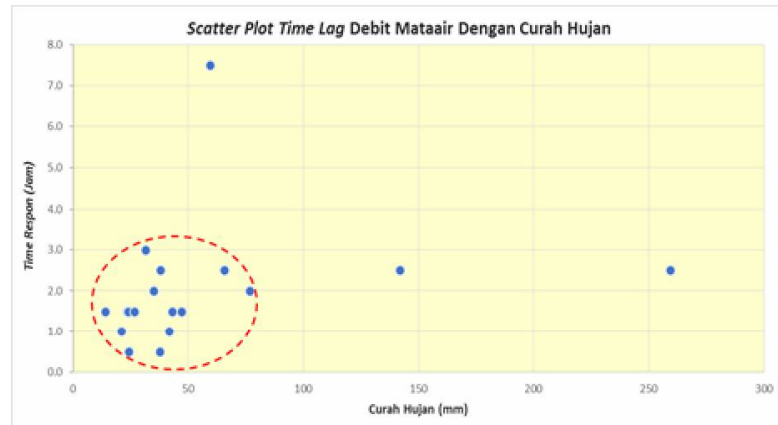

Gambar 4. Scatter Plot Time Lag Debit Mataair Terhadap Curah Hujan (Sumber: Olah data primer, 2014)

Hasil perhitungan menggunakan cross correlation menghasilkan nilai korelasi tertinggi respon aliran mataair terhadap curah hujan pada jeda waktu jam ke 2. Kondisi tersebut juga ditunjukan dengan melihat time lag rata-rata keseluruhan sampel kejadian banjir yang terjadi selama periode penelitian sebesar 2,03 jam. Selain itu, time lag yang ada untuk berbagai variasi curah hujan untuk keseluruhan kejadian banjir terpusat pada $0,5-3$ jam. Jeda waktu yang cukup singkat dari awal kejadian hujan hingga adanya kenaikan debit aliran mataair tersebut mengindikasikan bahwa sistem akuifer Mataair Ngeleng memiliki respon cepat. Respon cepat inilah yang menggambarkan sudah berkembangnya sistem rekahan yang cukup besar (Conduit ataupun fissure) pada sistem akuifer Mataair Ngeleng.

Indikasi terdapatnya sistem rekahan pada akuifer daerah kajian secara lebih lanjut akan 
Naskah publikasi skripsi-S1 Igor Yoga Bahtiar (belum diterbitkan)

dijelaskan dengan menganalisis aliran debit mataair pada sisi resesi hidrograf aliran debit martaair dan pemisahan aliran dasar. Analisis tersebut akan memberikan informasi mengenai jenis komponen aliran yang dikeluarkan oleh sistem akuifer karst, sehingga dapat diketahui perkembangan akuifer karst daerah kajian. Terdapat 17 sampel banjir yang dianalisis dari 27

kejadian banjir yang tercatat pada periode penelitian ini. Penentuan sampel banjir didasari oleh lama waktu resesi dari puncak banjir hingga kembali pada aliran dasar ( $t b=$ time to baseflow). Oleh karena itu, banjir kecil dan memiliki waktu resesi pendek kurang baik untuk digunakan sebagai sampel dalam perhitungan.

Tabel 1. Hasil Perhitungan Konstanta Resesi, Tb dan Tp Mataair Ngeleng

\begin{tabular}{|c|c|c|c|c|c|c|c|c|c|}
\hline \multirow[b]{2}{*}{ No } & \multicolumn{2}{|c|}{ Waktu } & \multirow{2}{*}{$\begin{array}{c}\text { Debit Puncak } \\
\text { (Lt/dt) }\end{array}$} & \multirow{2}{*}{$\begin{array}{c}\text { Kr Baseflow } \\
\text { (Kb) }\end{array}$} & \multirow{2}{*}{$\begin{array}{l}\text { Kr interflow } \\
\text { (Ki) }\end{array}$} & \multirow{2}{*}{$\begin{array}{c}\text { Kr Channel } \\
\text { (Kc) }\end{array}$} & \multirow[b]{2}{*}{ Tp (Jam) } & \multirow[b]{2}{*}{$\mathbf{T b}(\mathrm{Jam})$} & \multirow[b]{2}{*}{$\begin{array}{c}\text { Persentase } \\
\text { Baseflow (\%) }\end{array}$} \\
\hline & Tanggal & Jam & & & & & & & \\
\hline 1 & $11 / 11 / 2013$ & $22: 00$ & 39.61 & 0.9970 & 0.7008 & 0.6016 & 4.5 & 13.0 & 78.22 \\
\hline 2 & $14 / 11 / 2013$ & 01:00 & 42.54 & 0.9931 & 0.5793 & 0.4488 & 5.0 & 12.0 & 76.28 \\
\hline 3 & $15 / 11 / 2013$ & $16: 00$ & 39.46 & 0.9968 & 0.5478 & 0.3269 & 7.0 & 42.5 & 86.91 \\
\hline 4 & $17 / 11 / 2013$ & $17: 00$ & 36.45 & 0.9974 & 0.4695 & & 2.5 & 17.0 & 97.91 \\
\hline 5 & $19 / 11 / 2013$ & $07: 00$ & 51.67 & 0.9989 & 0.8247 & 0.3858 & 5.0 & 10.5 & 79.88 \\
\hline 6 & $21 / 11 / 2013$ & 01:00 & 158.72 & 0.9942 & 0.9573 & 0.6435 & 25.0 & 86.5 & 42.63 \\
\hline 7 & $25 / 11 / 2013$ & $03: 30$ & 72.09 & 0.9961 & 0.9365 & & 4.5 & 15.0 & 54.49 \\
\hline 8 & $11 / 12 / 2013$ & $19: 30$ & 46.42 & 0.9966 & 0.8589 & 0.4566 & 4.0 & 12.0 & 77.04 \\
\hline 9 & $20 / 12 / 2013$ & $12: 00$ & 134.37 & 0.9925 & 0.6641 & 0.3807 & 10.5 & 69.0 & 42.00 \\
\hline 10 & $5 / 1 / 2014$ & $08: 00$ & 34.34 & 0.9967 & 0.6768 & & 5.5 & 8.5 & 98.69 \\
\hline 11 & $10 / 1 / 2014$ & $00: 00$ & 34.21 & 0.9970 & 0.7701 & & 4.5 & 9.0 & 97.04 \\
\hline 12 & $15 / 1 / 2014$ & $11: 30$ & 36.88 & 0.9974 & 0.5432 & & 4.5 & 15.5 & 97.48 \\
\hline 13 & $10 / 2 / 2014$ & $22: 30$ & 67.66 & 0.9993 & 0.9165 & 0.2433 & 3.5 & 21.0 & 50.79 \\
\hline 14 & $18 / 2 / 2014$ & $21: 30$ & 34.34 & 0.9995 & 0.5695 & 0.4567 & 3.0 & 15.0 & 91.80 \\
\hline 15 & $23 / 2 / 2014$ & $21: 30$ & 40.73 & 0.9994 & 0.8940 & 0.6165 & 2.5 & 29.0 & 81.02 \\
\hline 16 & $3 / 3 / 2014$ & $11: 30$ & 33.80 & 0.9998 & 0.5056 & & 3.0 & 13.0 & 92.81 \\
\hline 17 & $12 / 4 / 2014$ & $19: 30$ & 30.25 & 0.9979 & 0.8514 & 0.3743 & 5.0 & 20.5 & 97.81 \\
\hline \multicolumn{4}{|c|}{ Rerata } & 0.9970 & 0.7215 & 0.4486 & 5.9 & 24.1 & 78.99 \\
\hline
\end{tabular}

Sumber: Hasil olah data primer, 2014

Berdasarkan hasil perhitungan pada Tabel 1. Maaair Ngeleng secara keseluruhan diketahui memiliki setiap komponen aliran yang menyuplai aliran resesi mataair, yaitu aliran conduit, fissure, dan diffuse. Komponen aliran conduit mataair ini memiliki julat konstanta resesi (Kc) 0,2433 0,6435 yang terdeteksi pada 11 kejadian banjir dari seluruh sampel banjir yang telah ditentukan. Nilai rata-rata dari variasi konstanta conduit sebesar 0,4486. Nilai konstanta tersebut memberikan makna bahwa komponen aliran conduit memiliki waktu konsentrasi paling pendek dalam menyupai keseluruhan aliran mataair daripada komponen aliran lain. Kondisi ini turut dibuktikan dengan rentang waktu $\mathrm{Tp}$ (Time to peak) kejadian banjir yang bervariasi dari 2,5 - 25 jam dengan rata-rata dari keseluruhan banjir 5,9 jam. Waktu menuju puncak banjir yang cepat menunjukan keikutsertaan suplai dari komponen aliran conduit. Hal tersebut didasari oleh sifat aliran conduit yang mempunyai respon yang cepat terhadap imbuhan yang masuk kedalam sistem aliran karst akibat adanya lorong-lorong batuan

karbonat berdiameter cukup besar (Atkinson, 1977; Gunn, 1986, dalam Bonnaci, 1993). Selain itu keberadaan komponen aliran conduit juga dipengaruhi oleh kondisi fisik Mataair Ngeleng yang bersifat terbuka (Oktama, 2014). Kejadian banjir yang terjadi dengan aliran mataair yang keruh (Gambar 5.) juga memperkuat indikasi adanya komponen aliran conduit.

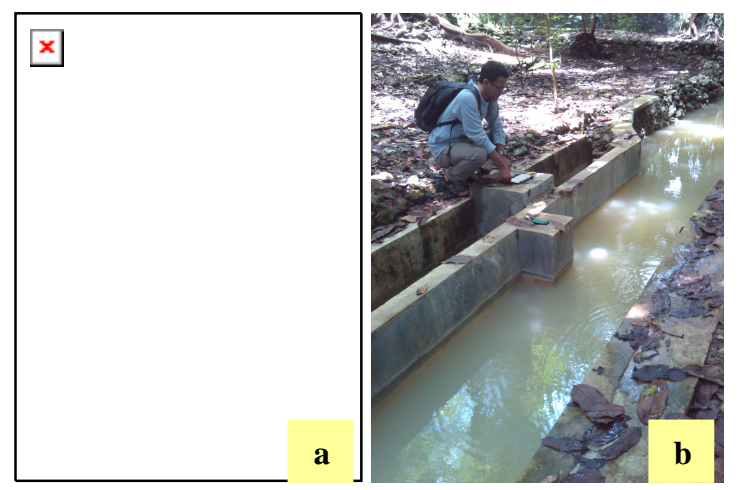

Gambar 5. a.Kondisi normal aliran mataair dan b.Kondisi aliran mataair yang keruh ketika banjir.

(Sumber: Dokumentasi Lapangan, 2013-2014)

Keberadaan komponen aliran fissure yang ikut serta menyuplai aliran mataair 
Naskah publikasi skripsi-S1 Igor Yoga Bahtiar (belum diterbitkan)

terdeteksi disetiap kejadian banjir dari sampel yang ada. Komponen aliran ini memiliki julat koefisien resesi (Ki) 0,4695 - 0,9573 dengan rata-rata nilai Ki sebesar 0,7215. Rentang nilai Ki yang cukup bervariasi menunjukan bahwa komponen aliran fissure pada Mataair Ngeleng memiliki waktu suplai terhadap aliran mataair yang bervariasi. Namun komponen aliran ini memiliki waktu suplai yang lebih lama daripada komponen aliran conduit dan lebih pendek daripada komponen aliran diffuse.

Komponen aliran mataair yang terusmenerus mengisi aliran adalah komponen aliran diffuse. Aliran diffuse yang setara dengan baseflow memiliki nilai konstanta $(\mathrm{Kb}) 0,9925$ 0,9998 dengan rata-rata 0,9970 dari perhitungan keseluruhan sampel banjir. Nilai konstanta yang besar tersebut memberikan indikasi bahwa komponen aliran diffuse pada Mataair Ngeleng memiliki berkontribusi paling lama dalam menyuplai aliran mataair. Kondisi ini dibuktikan dengan selalu adanya aliran mataair sepanjang tahun baik ketika musim hujan maupun ketika musim kemarau. Disisi lain Tb (time to base) yaitu waktu aliran dari puncak banjir menuju baseflow pada Mataair Ngeleng memiliki variasi waktu dari 8,5 - 86,5 jam dengan rata-rata $\mathrm{Tb}$ 24,1 jam. Durasi $\mathrm{Tb}$ yang cukup panjang dibandingkan dengan Tp memberikan informasi bahwa suplai aliran mataair tidak hanya didominasi oleh komponen aliran diffuse/baseflow. Komponen lain (conduit dan fissure) juga turut serta dalam memberikan masukan pada aliran Mataair Ngeleng.

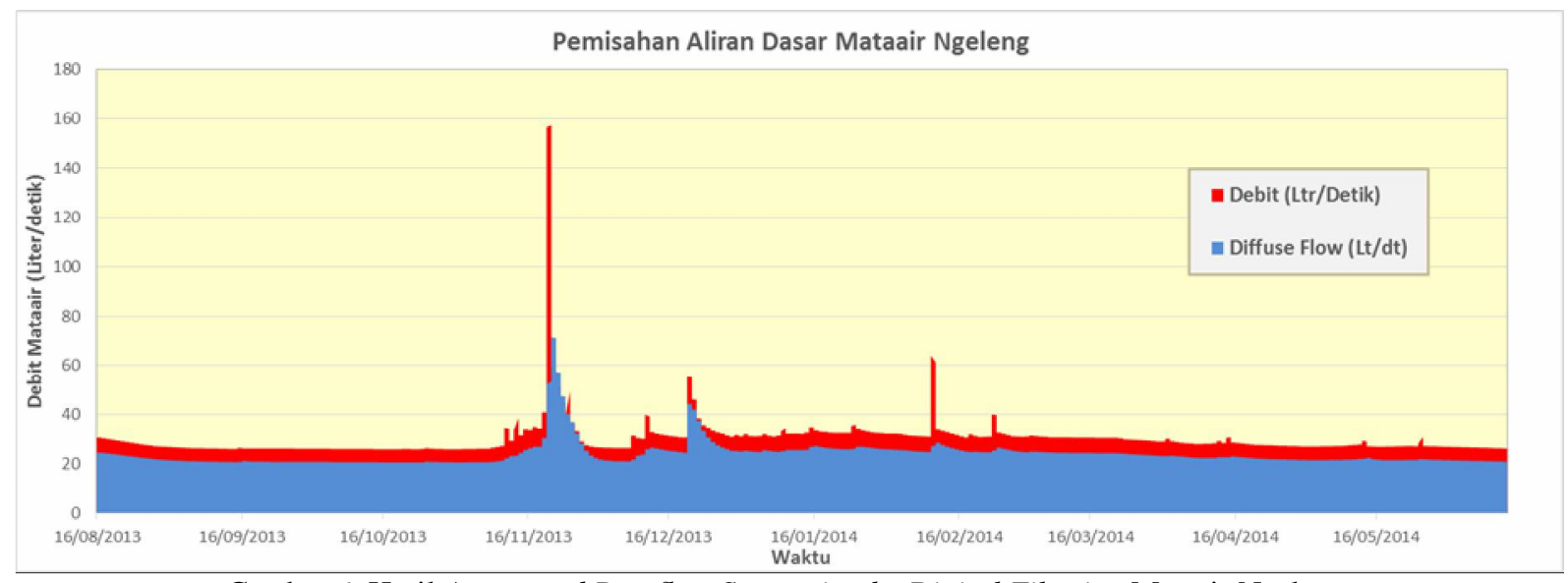

Gambar 6. Hasil Automated Baseflow Separation by Digital Filtering Mataair Ngeleng.

(Sumber: Olah data primer, 2014)

Menurut Eckhardt (2012) tujuan dari pemisahan aliran dasar adalah untuk membedakan komponen aliran dasar/baseflow dengan komponen aliran cepat/quickflow. Quickflow atau aliran cepat yang dimaksud pada kondisi ini adalah komponen aliran conduit dan fissure. Pemisahan aliran dasar dilakukan dengan metode Automated Baseflow Separation by Digital Filtering yang (Eckhardt, 2005 dalam Adji 2009). Eckhardt (2012) juga memberikan pemahaman bahwa dengan kondisi akuifer yang terbentuk dari media porus dan aliran yang mengalir sepanjang tahun, maka nilai BFImax yang digunakan adalah 0,8 . Sedangkan konstanta aliran dasar $(\mathrm{Kb})$ Mataair Ngeleng sebesar 0,997 berdasarkan hasil perhitungan konstanta resesi sebelumnya. Pemisahan aliran dasar ini kemudian digunakan untuk mengetahui perbandingan aliran dasar dengan debit aliran mataair keseluruhan guna mengetahui perilaku komponen aliran dalam menyuplai aliran mataair. Hasil pemisahan aliran dasar Mataair Ngeleng selama periode penelitian dapat diketahui pada Gambar 6.

Tabel 2. Persentase Aliran Dasar Bulanan

\begin{tabular}{|l|c|c|}
\multicolumn{1}{|c|}{ Mataair Ngeleng } \\
\hline Bulan & $\begin{array}{c}\text { Persentase } \\
\text { Baseflow (\%) }\end{array}$ & Musim \\
\hline Oktober & 80.11 & Kemarau \\
\hline November & 79.79 & Kemarau \\
\hline Desember & 79.65 & Hujan \\
\hline Januari & 79.89 & Hujan \\
\hline Februari & 80.13 & Hujan \\
\hline Maret & 80.26 & Hujan \\
\hline April & 80.26 & Hujan \\
\hline Mei & 80.02 & Kemarau \\
\hline Rata-rata & $\mathbf{8 0 . 0 1}$ & \\
\hline
\end{tabular}

Sumber: Olah data primer, 2014 
Naskah publikasi skripsi-S1 Igor Yoga Bahtiar (belum diterbitkan)

Variasi presentase aliran dasar bulanan Mataair Ngeleng dapat dilihat pada Tabel 2. Berdasarkan tabel tersebut diketahui bahwa presentase aliran dasar bulanan Mataair Ngeleng memiliki rata-rata presentase aliran dasar 80,01 $\%$ selama periode penelitian. Rentang nilai presentase yang tidak jauh berbeda antara 79,65 - 80,26 \% menunjukan kesetabilan imbuhan dari aliran dasar dari akuifer mataair tersebut. Kondisi ini mengindikasikan dominasi dari aliran diffuse pada akuifer karst Mataair Ngeleng.

Tabel 2. di atas memberikan informasi terdapat pola pada komposisi dari persentase aliran dasar bulanan. Pada bulan November Januari mengalami penurunan persentase aliran dasar dibawah nilai $80 \%$. Perlu diketahui pada bulan-bulan tersebut merupakan bulan dengan curah hujan yang tinggi sehingga banyak dijumpai kejadian banjir. Hal tersebut tentu saja menguatkan bahwa pada bulan-bulan tersebut komponen aliran conduit dan fissure memiliki kesempatan yang lebih banyak dalam suplai aliran mataair dibandingkan dengan bulan-bulan lainnya. Menurunnya persentase aliran dasar pada bulan-bulan tersebut menunjukan bahwa meningkatnya komponen aliran lain (komponen

aliran conduit dan fissure) dalam suplai aliran mataair. Adji (2011) menjelaskan bahwa pada musim hujan presentase aliran dasar cenderung menurun dan akan kembali naik seiring dengan berakhirnya musim hujan.

Nilai presentase aliran dasar (PAD) yang turun pada periode musim hujan mengindikasikan bahwa pasokan aliran lorong ataupun celah (conduit dan fissure) lebih mendominasi. Aliran cepat tersebut tentu saja merupakan respon dari adanya recharge pada periode musim hujan. Sehingga dengan dominasi aliran lorong dan celah tersebut, pasokan aliran dasar (diffuse) terhadap debit aliran mataair menjadi menurun. Secara umum dari periode musim hujan awal, tengah dan akhir dapat diketahui bahwa perilaku aliran dasar dan debit aliran mataair yang digambarkan dengan PAD memiliki perilaku yang berbeda dengan PAD bulanan. Perbedaan ini didasari oleh PAD keseluruhan sampel saat puncak banjir pada musim penghujan ini yang memiliki nilai dibawah $75 \%$ dengan kisaran 28,23-74,90\%. Tabel 3 . menunjukan rasio antara beberapa sampel debit puncak banjir dan aliran dasar selama periode penelitian.

Tabel 3. Rasio Aliran Dasar dengan Debit Puncak Banjir Terpilih Mataair Ngeleng.

\begin{tabular}{|c|c|c|c|c|c|c|c|}
\hline \multirow{2}{*}{$\begin{array}{l}\text { Period } \\
\text { e } \\
\text { Musim } \\
\text { Hujan }\end{array}$} & \multirow[b]{2}{*}{ No } & \multicolumn{2}{|c|}{ Waktu } & \multirow{2}{*}{$\begin{array}{c}\text { Debit Puncak } \\
\text { Banjir (Itr/dtk) }\end{array}$} & \multirow{2}{*}{$\begin{array}{c}\text { Baseflow } \\
\text { (ltr/dtk) }\end{array}$} & \multirow{2}{*}{$\begin{array}{c}\text { Persentase } \\
(\%)\end{array}$} & \multirow{2}{*}{$\begin{array}{c}\text { Rerata } \\
\text { Persentas } \\
\text { e Aliran } \\
\text { Dasar }(\%) \\
\end{array}$} \\
\hline & & Tanggal & Jam & & & & \\
\hline \multirow{5}{*}{$\begin{array}{c}\text { Periode } \\
\text { Awal }\end{array}$} & 1 & $11 / 11 / 2013$ & $22: 00$ & 39.61 & 22.09 & 55.77 & \multirow{5}{*}{60.36} \\
\hline & 2 & $14 / 11 / 2013$ & 01:00 & 42.54 & 23.75 & 55.83 & \\
\hline & 3 & $15 / 11 / 2013$ & $16: 00$ & 39.46 & 25.17 & 63.80 & \\
\hline & 4 & $17 / 11 / 2013$ & $17: 00$ & 36.45 & 26.57 & 72.91 & \\
\hline & 5 & $19 / 11 / 2013$ & 07:00 & 51.67 & 27.65 & 53.52 & \\
\hline \multirow{6}{*}{$\begin{array}{l}\text { Periode } \\
\text { Tengah }\end{array}$} & 6 & $11 / 12 / 2013$ & $19: 30$ & 46.42 & 24.70 & 53.22 & \multirow{6}{*}{62.16} \\
\hline & 7 & $20 / 12 / 2013$ & $12: 00$ & 134.37 & 37.93 & 28.23 & \\
\hline & 8 & $1 / 1 / 2014$ & $12: 00$ & 33.80 & 25.00 & 73.97 & \\
\hline & 9 & $5 / 1 / 2014$ & 08:00 & 34.34 & 25.05 & 72.93 & \\
\hline & 10 & $10 / 1 / 2014$ & 00:00 & 34.21 & 25.21 & 73.71 & \\
\hline & 11 & $15 / 1 / 2014$ & $11: 30$ & 36.88 & 26.14 & 70.87 & \\
\hline \multirow{5}{*}{$\begin{array}{c}\text { Periode } \\
\text { Akhir }\end{array}$} & 12 & $10 / 2 / 2014$ & $22: 30$ & 67.66 & 26.23 & 38.77 & \multirow{5}{*}{64.04} \\
\hline & 13 & $18 / 2 / 2014$ & $21: 30$ & 34.34 & 24.72 & 71.98 & \\
\hline & 14 & $23 / 2 / 2014$ & $21: 30$ & 40.73 & 24.94 & 61.24 & \\
\hline & 15 & $3 / 3 / 2014$ & $11: 30$ & 33.80 & 24.79 & 73.33 & \\
\hline & 16 & $12 / 4 / 2014$ & $19: 30$ & 30.25 & 22.66 & 74.90 & \\
\hline
\end{tabular}

Sumber: Olah data primer, 2014

Pola aliran dasar tidak mengikuti pola debit aliran mataair. Kenaikan aliran dasar pada seluruh kejadian banjir Mataair Ngeleng terjadi sesaat setelah debit aliran mataair mengalami penurunan dari puncak banjir. Meskipun

demikian, hubungan PAD dengan debit aliran selama periode awal, tengah dan akhir musim hujan ini menunjukan hubungan yang kuat. Hubungan kuat tersebut didasari dari korelasi antara PAD dengan debit aliran ketika mengalami kenaikan debit (rising limb) dan 
Naskah publikasi skripsi-S1 Igor Yoga Bahtiar (belum diterbitkan)

ketika mengalami penurunan debit (recession limb) menunjukan nilai determinasi (R2) 0,88 0,99 . Namun hubungan kedua variabel ini menunjukan hubungan yang berbanding terbalik. Kenaikan PAD diimbangi dengan penurunan debit aliran dan penurunan $\mathrm{PAD}$ merupakan konsekuensi dari kenaikan debit aliran.

\section{KESIMPULAN}

Berdasarkan temuan dan hasil pembahasan pada penelitian ini, maka dengan pertimbangan tujuan awal penelitian. Kesimpulan yang dapat diambil pada penelitian ini adalah sebagai berikut:

1. Pola korelasi recharge berupa curah hujan dengan discharge berupa debit aliran mataair menunjukan hubungan positif. Hubungan tersebut didasari dari korelasi sederhana antara dua variabel yang memiliki nilai korelasi (R) sebesar 0,630. Hasil sejalan juga ditunjukan oleh metode cross correlation, dimana korelasi tertinggi antara recharge dan discharge berada pada jeda waktu (time lag) jam ke-2 dengan nilai korelasi $\left(\mathrm{r}_{\mathrm{xy}}(\mathrm{k})\right)$ sebesar 0,281. Hasil metode tersebut dikuatkan oleh data faktual variasi temporal periode musim hujan dengan kenaikan awal debit mataair yang terjadi pada interval waktu $0,5-3$ jam dari berbagai variasi besar curah hujan. Nilai rata-rata time lag dari kejadian banjir selama periode penelitian juga menunjukan waktu jeda kenaikan debit selama 2,02 jam dari awal kejadian hujan. Oleh karena itu, dapat diartikan bahwa akuifer karst Mataair Ngeleng memiliki respon berupa kenaikan aliran debit mataair pada jeda waktu \pm 2 jam dari awal kejadian hujan. Respon cepat tersebut mengindikasikan bahwa sistem akuifer karst Mataair Ngeleng memiliki komponen aliran cepat (conduit dan fissure) yang merupakan hasil dari perkembangan rekahan yang telah menjadi celah ataupun saluran yang lebih besar. Indikasi tersebut dikuatkan oleh hasil analisis komponen aliran pada hidrograf banjir selama periode penelitian.

2. Hasil analisis komponen aliran mataair Ngeleng menunjukan bahwa mataair tersebut memiliki dominasi aliran diffuse (rembesan) dan sudah berkembangnya aliran fissure (celah) maupun conduit (saluran). Kondisi tersebut terlihat berdasarkan nilai konstanta resesi Mataair Ngeleng 0,9970 untuk rata-rata nilai konstanta resesi komponen aliran diffuse $(\mathrm{Kb}) ; 0,7215$ untuk ratarata nilai konstanta resesi komponen aliran fissure (Ki); dan 0,4486 untuk rata-rata nilai konstanta resesi komponen aliran conduit $(\mathrm{Kc})$. Dominasi aliran diffuse pada mataair terlihat dari presentase aliran dasar (PAD) bulanan yang cenderung stabil pada angka 79,79 - 80,26 \% selama periode penelitian. Keberadaan komponen aliran fissure dan conduit dibuktikan dengan besar nilai PAD puncak banjir untuk keseluruhan kejadian banjir periode awal, tengah dan akhir musim hujan yang berada pada nilai $<75 \%$ dengan nilai PAD terkecil 28,23 $\%$ dan tertinggi $74,90 \%$. Hubungan yang berbanding terbalik antara PAD dan debit aliran juga memberikan indikasi bahwa pada saat kenaikan debit mataair aliran dasar cenderung tertekan oleh adanya aliran cepat (conduit dan fissure). Indikasi ini memperkuat kesimpulan sebelumnya, sehingga dapat dikatakan bahwa sistem akuifer karst Mataair Ngeleng memiliki karakter respon debit yang cepat terhadap curah hujan yang disebabkan oleh sudah berkembangnya sistem akuifer pada batuan karbonat dengan indikasi adanya rekahan kecil (diffuse), celah (fissure) dan rekahan besar berupa saluran (conduit).

\section{DAFTAR PUSTAKA}

Adji, T. N. 2011. Pemisahan Aliran Dasar Bagian Hulu Sungai Bribin pada Aliran Gua Gilap, di Kars Gunung Sewu, Gunung Kidul, Yogyakarta. Jurnal Geologi Indonesia, Vol 6 No. 3, Hal. 165-175.

Adji, T. N., 2010. Variasi Spasial-Temporal Hidrogeokimia dan Sifat Aliran Untuk Karakterisasi Sistem Karst Dinamis Di Sungai Bawah Tanah Bribin, Kabupaten Gunungkidul, DIY. Desertasi. Fakultas Geografi, Universitas Gadjah Mada.

Adji, T. N., 2010. Spatial and Temporal Variation of Hydrogeochemistry and Karst Flow Properties to Characterize Karst Dynamic System in Bribin Underground River, Gunung Kidul Regency, DIY Province Java, Indonesia. Summary, Dissertation in Geography Study Program. Graduate School of Geography, Gadjah Mada University, Yogyakarta

Adji, T. N., et al. 2006. The Distribution Of Flood Hydrograph Recession Constant Of Bribin River For Gunung Sewu Karst Aquifer Characterization. Dipublikasi ulang dari Gunung Sewu-Indonesian Cave and Karst Journal (Vol. 2. No.2)

Adji, T.N. 2012, Wet Season Hydrochemistry of Bribin River in Gunung Sewu Karst, Indonesia, Environmental Earth Sciences, Vol. 67:1563-1572 pp

Adji, T.N. dan Haryono, E., 1999. Konflik Antara Pemanfaatan Batugamping dan Konservasi Sumberdaya Air Das Bribin di Wilayah Karst Gunung Sewu, Makalah Lokakarya Nasional Menuju Pengelolaan Sumberdaya Wilayah Berbasis Ekosistem 
Naskah publikasi skripsi-S1 Igor Yoga Bahtiar (belum diterbitkan)

Untuk Mereduksi Konflik Antar Daerah, Yogjakarta, , Fakultas Geografi, Universitas Gadjah Mada, September 1999

Adji, T.N., 2005, Agresivitas Airtanah Karst Sungai Bawah Tanah Bribin, Gunung Sewu, Indonesian Cave and Karst Journal, Vol. 1 No1, HIKESPI

Adji, T.N., 2011. Pemisahan aliran dasar bagian hulu Sungai Bribin pada aliran Gua Gilap, di Karst Gunung Sewu, Gunung Kidul, Yogyakarta, Jurnal Geologi Indonesia, Vol. 6 No. 3 September 2011

Adji, T.N., 2013, Hubungan Karakter Aliran dan Sifat Kimia Mataair Petoyan Untuk Karakterisasi Akuifer Karst, Hibah Dana Masyarakat Fak. Geografi UGM

Adji, T.N., 2014, Analisis Hidrograf Aliran Untuk Penentuan Derajat Karstifikasi Pada Beberapa Kondisi Mataair dan Sungai Bawah Tanah Karst, Hibah Dana Masyarakat Fak. Geografi UGM

Adji, T.N., Haryono, E., Woro, S, 1999, Kawasan Karst dan Prospek Pengembangannya di Indonesia, Seminar PIT IGI di Universitas Indonesia, 26-27 Oktober 1999

Adji, T.N., Hendrayana, H., Sudarmadji, dan Suratman, W., 2009. Diffuse Flow Separation Within Karst Underground River At Ngreneng Cave. Proceeding of International Conference Earth Science and Technology, 6-7 Aug, Yogyakarta.

Adji, T.N., Misqi, M., 2010, The Distribution of Flood Hydrograph Recession Constant for Characterization of Karst Spring and Underground River Flow Components Releasing Within Gunung Sewu Karst Region, Indonesian Journal of Geography, XLII(1)

Adji, T.N., Sudarmadji, Suprojo, S.W., Hendrayana, H., Hariadi, B., 2007. The Distribution of Flood Hydrograph Recession Constant of Bribin River for Gunung Sewu Karst Aquifer Characterization, Proceeding of International Symposium on Earth Resources and Geological Engineering Educational , 17-18 Dec 2007, Jogjakarta

Bonacci, O. 1993. Karst Springs Hydrographs as Indicators of Karst Aquifer. Hydrological Science Journal des Sciences Hydrologiques, 38, p51-62.

Budge, T. J., 2009. Modeling the Usefulness of Spatial Correlation Analysis on Karst Systems. Ground Water Journal Wiley-Blackwell Vol: 47, no. 3 (Pages 427437).

Eckhardt K, 2005. How to construct recursive digital filters for baseflow separation. Hydrological Processes 19, 507-515.

Eckhardt, K. 2012. Technical Note: Analytical Sensitivity Analysis Of A Two Parameter Recursive Digital Baseflow Separation Filter. Hydrology Earth System. Sci., 16, 451-455, 2012 Published by Copernicus Publications on behalf of the European Geosciences Union.
Fiorillo, F. dan Doglioni, A., 2010. The Relation Between Karst Spring Discharge and Rainfall By CrossCorrelation Analysis (Campania, southern Italy). Hydrogeology Journal (2010) 18: 1881-1895, Springer-Verlag.

Hartono, 2008. SPSS 16.0 Analisis Data Statistika dan Penelitian. Yogyakarta: Pustaka Pelajar.

Haryono, E. dan Adji, T.N. 2004. Geomorfologi dan Hidrologi Karst. Yogyakarta: Kelompok Studi Karst, Fakultas Geografi, Universitas Gadjah Mada

Oktama, R., 2014. Karakterisasi Akuifer Karst Mataair Ngeleng Dengan Pendekatan Variasi Temporal Sifat Aliran dan Hidrogeokimia. Skirpsi. Fakultas Geografi, UGM

Schulz, E.F. 1976. Problems in Applied Hydrology. Water Resources Publication, Colorado.

Thomas, B.C., 2010. Comparison Of Two PhysicallyBased Spatially Distributed Hydrology Models In Contrasting Geo-Climatic Settings. Thesis. Faculty of Geo-information Science and Earth Observation (ITC).

Zhang, Z., Chen, Xi, Chen X., dan Shi, P., 2013. Quantifying Time Lag of Epikarst-Spring Hydrograph Response to Rainfall Using Correlation and Spectral Analyses. Hydrogeology Journal (2013) 21: 16191631 Springer-Verlag Berlin Heidelberg. 